\title{
On the Free Terms of the Dual BEN for the Two and Three-Dimensional Laplace Problems
}

\author{
Jeng-Tzong Chen \\ Professor, Department of Harbor and River Engineering, Taiwan Ocean University, Keelung, Taiwan 202, R.O.C. \\ Shyh-Rong Kuo \\ Professor, Department of Harbor and River Engineering, Taiwan Ocean University, Keelung, Taiwan 202, R.O.C. \\ Wei-Chih Chen \\ Professor, Department of Harbor and River Engineering, Taiwan Ocean University, Keelung, Taiwan 202, R.O.C. \\ Li-Wei Liu \\ Professor, Department of Harbor and River Engineering, Taiwan Ocean University, Keelung, Taiwan 202, R.O.C.
}

Follow this and additional works at: https://jmstt.ntou.edu.tw/journal

Part of the Civil and Environmental Engineering Commons

\section{Recommended Citation}

Chen, Jeng-Tzong; Kuo, Shyh-Rong; Chen, Wei-Chih; and Liu, Li-Wei (2000) "On the Free Terms of the Dual BEN for the Two and Three-Dimensional Laplace Problems," Journal of Marine Science and Technology. Vol. 8: Iss. 1, Article 2. DOI: $10.51400 / 2709-6998.2449$

Available at: https://jmstt.ntou.edu.tw/journal/vol8/iss1/2

This Research Article is brought to you for free and open access by Journal of Marine Science and Technology. It has been accepted for inclusion in Journal of Marine Science and Technology by an authorized editor of Journal of Marine Science and Technology. 


\title{
ON THE FREE TERMS OF THE DUAL BEM FOR THE TWO AND THREE-DIMENSIONAL LAPLACE PROBLEMS
}

\author{
Jeng-Tzong Chen*, Shyh-Rong Kuo, Wei-Chih Chen and Li-Wei Liu
}

Keywords: dual boundary integral equations, dual boundary element method, a smooth boundary, free term, Laplace equation.

\section{ABSTRACT}

A dual integral formulation for the Laplace problem with a smooth boundary is derived by using the contour approach surrounding the singularity. It is found that using the contour approach the jump terms come half and half from the free terms in the $L$ and $M$ kernel integrations for the two-dimensional case, which is different from the limiting process by approaching an interior point to a boundary point where the jump terms come totally from the $L$ kernel only. The definition of the Hadamard principal value for hypersingular integral at the collocation point of a smooth boundary is extended to a generalized sense for both the tangent and normal derivatives of double-layer potentials in comparison with the conventional definition. For the threedimensional case, the jump terms come one-third and two-thirds from the free terms of $L$ and $M$ kernels, respectively.

\section{INTRODUCTION}

A dual integral formulation for crack problems was developed in 1986 [5] and published in 1988 [23]. It was applied to the Laplace equation with a degenerate boundary $[6,9]$. The numerical implementation has been termed the dual boundary element method by Portela et al. [34]. The formulations have been mainly applied to problems with a degenerate boundary [11], e. g., a screen in acoustic cavity [10], a crack in elastic body [23] and a cutoff wall in potential flow [7, 8]. Recently, the hypersingular equation has been utilized

Paper Received Feb. 17, 2000. Author for Correspondence: J. T. Chen. *Professor, Department of Harbor and River Engineering, Taiwan Ocean University, Keelung, Taiwan 202, R.O.C. to provide a constraint at a corner in an analytical way [15, 17-20]. Gray and Manne [20] have applied the hypersingular equation as an additional constraint to ensure a unique solution by a limiting process from an interior point to a corner. The three-dimensional case was also extended by Gray and Lutz [18]. How to accurately determine the free term in hypersingular equation has received much attention in the dual boundary element method [21, 30-32]. From the viewpoint of dual integral equations, singular and hypersingular equations can provide sufficient constraints for a singular system with a corner. In the case of a nonsmooth boundary, e.g., a corner point, the jump terms of singular and hypersingular integral equations are the same in the former derivations as reported by Lutz et al. [28] and Chen and Hong [7]. Later, an additional free term in the hypersingular equation was found by Chen and Hong [9, 27]. Since the hypersingular integral equation can provide an additional constraint for the problem with the Dirichlet boundary conditions, the free terms on a smooth boundary by approaching the interior domain to the exterior domain must be examined [26]. Many researchers, for example, Guiggiani [21], has derived the free terms for the Laplace and the Navier equations. However, they did not discuss the difference of the results between the limiting approach and the bump contour method. To derive the free terms in a hypersingular equation, the bump-contour approach around the singularity can be considered and can be compared with the limiting process by using an analytical integral. Therefore, the dual integral equations for a smooth boundary can be derived. Following the same symbols as in the reference [9] of $U, T, L$ and $M$ kernels for single-layer kernel and its normal derivative, doublelayer kernel and its normal derivative, respectively, the bump contour method will be adopted to determine the free terms. Two alternatives for constraint equations can be chosen: (1) by using the $U T$ equation; (2) by using the $L M$ equation. A detailed review about dual integral equations and dual BEM can be found in [11]. Both the free terms of the two-dimensional and threedimensional problems will be examined by using the 
Table 1. Properties of different kinds of potentials across smooth boundary.

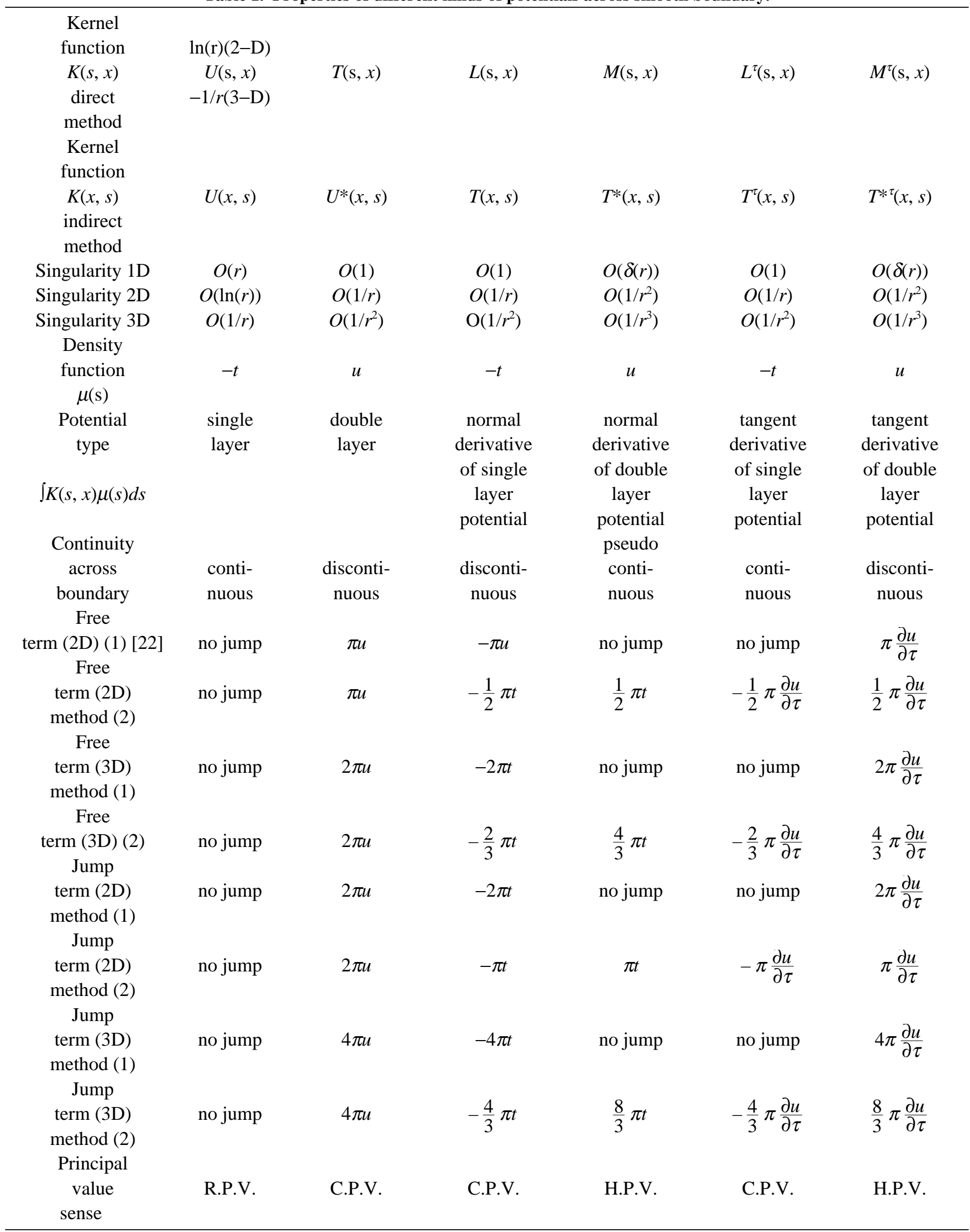




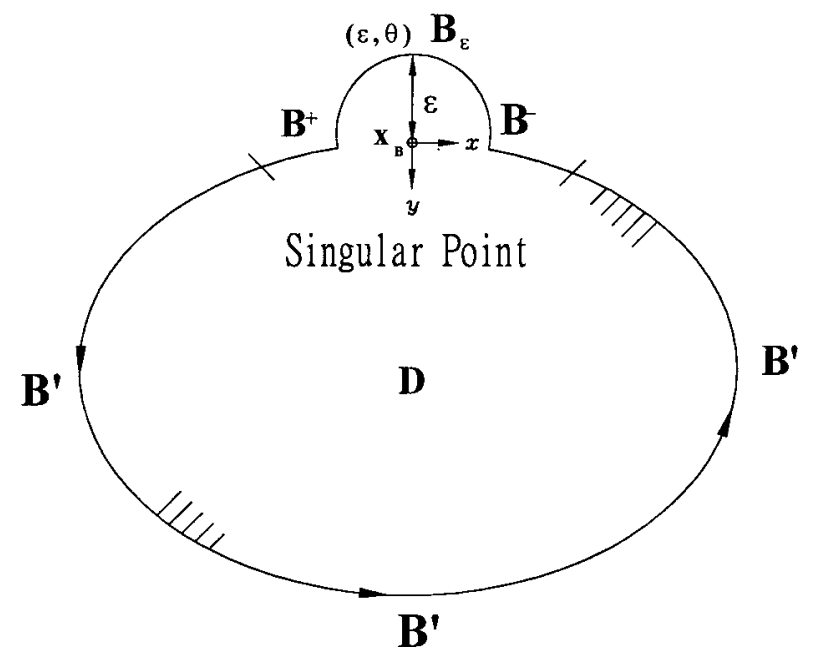

Fig. 1. The considered boundary integration path for the two-dimensional Laplace problem.

bump contour approach in this paper. Their results will be compared with those derived by using the limiting process.

\section{FREE TERMS OF DUAL INTEGRAL FORMULATION WITH A SMOOTH BOUNDARY FOR THE TWO DIMENSIONAL CASE}

The dual boundary integral equations for the potential $u$ can be derived as

$$
\begin{aligned}
2 \pi u(x) & =\int_{B^{\prime}+B^{-}+B_{n^{+}} B^{+}}\{T(s, x) u(s) \\
& -U(s, x) t(s)\} d B(s) \\
2 \pi t(x) & =\int_{B^{\prime}+B^{-}+B_{n^{+}} B^{+}}\{M(s, x) u(s) \\
& -L(s, x) t(s)\} d B(s) \\
2 \pi \frac{\partial u(x)}{\partial \tau} & =\int_{B^{\prime}+B^{-}+B_{n^{+}} B^{+}}\left\{M^{\tau}(s, x) u(s)\right. \\
& \left.-L^{\tau}(s, x) t(s)\right\} d B(s)
\end{aligned}
$$

where $u(s)$ and $t(s)$ denote the potential and its normal flux on the boundary point $s$, respectively, $B^{\prime}, B^{-}, B_{\mathrm{n}}$ and $B^{+}$are the contour integration paths including the singularity inside the domain, $D$, as shown in Fig. 1, and $U$, $T, L, M, L^{\tau}$ and $M^{\tau}$ are the six kernel functions [9] in the dual integral equations with the properties shown in Table 1. The $U, M$ kernels are weakly singular and hypersingular, respectively, while the $T, L$ kernels are strongly singular. For the single and double-layer

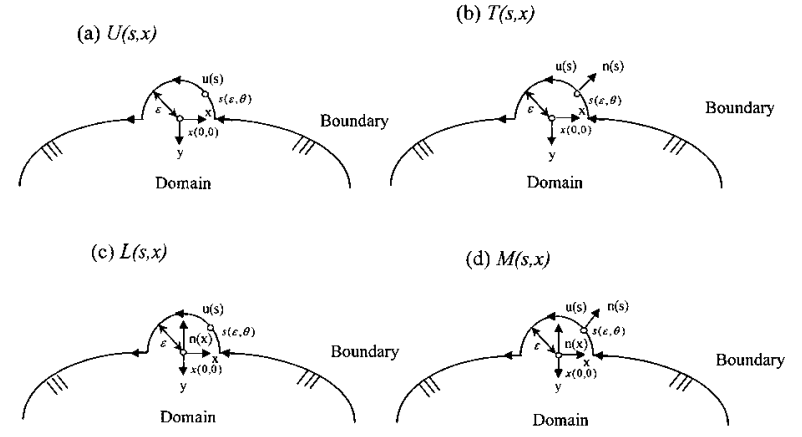

Fig. 2. Related symbols around a smooth boundary for the two-dimensional Laplace problem.

kernels, Aliabadi et. al [2, 3] have employed the Taylor expansion to reduce the singularity order. Eq. (2) and Eq. (3) are different in the direction of derivative on the collocation point $x$. The direction of derivative of the former one is normal, the latter is tangent. The superscript " $\tau$ " of the kernels in Eq. (3) denotes the tangent vector along the boundary. The $B$ integration path in Fig. 1 denotes the contour integration around the singularity with a radius $\mathrm{n}$, and $B^{\prime}+B^{+}+B^{-}$is just the definition of the integration region of the Cauchy principal value. $B^{+}$and $B^{-}$denote two of the elements in the $B$ ' boundary near the singularity as shown in Fig. 1 . First of all, we will integrate the $B$ path integration to obtain the free terms for the six kernel functions.

Without loss of generality, we have the following notations in Fig. 1 and Fig. 2:

$$
\begin{aligned}
& x=(0,0) \\
& s=(\mathrm{n} \cos (\theta),-\mathrm{n} \sin (\theta)) \\
& r=|x-s| \\
& y_{1}=-\mathrm{n} \cos (\theta) \\
& y_{2}=\mathrm{n} \sin (\theta) \\
& n(s)=\left(n_{1}, n_{2}\right)=(\cos (\theta),-\sin (\theta)) \\
& n(x)=\left(\bar{n}_{1}, \bar{n}_{2}\right)=(0,1) \text { for normal derivative } \\
& \tau=\left(\bar{n}_{1}, \bar{n}_{2}\right)=(1,0) \text { for tangent derivative } \\
& u(s)=u(x)+\left.\frac{\partial u}{\partial x}\right|_{s=x} n \cos (\theta)-\left.\frac{\partial u}{\partial y}\right|_{s=x} n \sin (\theta) \\
& t(s)=\frac{\partial u(s)}{\partial s_{1}} \cos (\theta)-\frac{\partial u(s)}{\partial s_{2}} \sin (\theta)
\end{aligned}
$$

where $\tau$ in Eq. (11) denotes the tangent vector on the 
boundary point $x$ with the components $(1,0)$ as shown in Fig. 2, and $\pi$ is the interior angle of the smooth boundary.

According to the related symbols in Fig. 2, the free terms of the six kernels on the two-dimensional case will be derived in the following.

(1). Single-layer potential due to

$U(s, x)=\ln (r)=\ln (\mathrm{n})$ :

$$
\int_{B_{n}} U(s, x) t(s) d B(s)=n \ln (n) \text { (finite value) }
$$

The free term is zero since $n \ln (n)$ approaches zero as the radius $n$ approaches zero.

(2). Double-layer potential due to

$T(s, x)=-y_{i} n_{i} / r^{2}=1 / \mathrm{n}$ :

$$
\int_{B_{n}} T(s, x) u(s) d B(s)=\pi u(x)+n(\text { finite value })
$$

As $\mathrm{n}$ approaches zero, the free term is $\pi u(x)$.

(3). Normal derivative of single-layer potential due to $L(s, x)=y_{i} \bar{n}_{i} / r^{2}=\sin (\theta) / \mathrm{n}$ :

$$
\int_{B_{n}} L(s, x) t(s) d B(s)=-\frac{\pi}{2} t(x)
$$

As $n$ approaches zero, the free term is $-\frac{\pi}{2} t(x)$.

(4). Normal derivative of double-layer potential due to $M(s, x)=2 y_{i} y_{j} n_{i} \bar{n}_{j} / r^{4}-n_{i} \bar{n}_{i} / r^{2}=-\sin (\theta) / n^{2}$

$$
\int_{B_{n}} M(s, x) u(s) d B(s)=\frac{\pi}{2} t(x)+\text { Boundary term }
$$

where the boundary term $B(\mathrm{n})$ is

$$
B(n)=-\frac{2}{n} u(x)
$$

It is interesting to find that the free terms from the $L$ and $M$ kernels are the same except for the minus sign. The free terms resulted from the $M$ kernel contain the boundary term, which is infinite as $\mathrm{n}$ approaches zero in Eq. (18). By combining with the Cauchy principal value of the $M$ kernel integration over $B^{\prime}$ including $B^{+}$and $B^{-}$as shown in Fig. 1, the finite part can be extracted, and the infinity can be cancelled out. Therefore, the Hadamard principal value in the contour integration with a smooth boundary for the $M$ kernel can be defined by

$$
\begin{aligned}
& \text { H.P.V. } \int_{B} M(s, x) u(s) d B(s) \\
& =\text { C.P.V. } \int_{B} M(s, x) u(s) d B(s)-\frac{2}{n} u(x)
\end{aligned}
$$

(5). Tangent derivative of single-layer potential due to $L^{\tau}(s, x)=y_{i} \bar{n}_{i} / r^{2}=-\cos (\theta) / n$ :

Since the tangent derivative instead of the normal derivative is considered, we have

$$
\begin{aligned}
& n(x) \rightarrow \tau \\
& \int_{B_{n}} L^{\tau}(s, x) t(s) d B(s)=-\frac{\pi}{2} \frac{\partial u(x)}{\partial \tau}
\end{aligned}
$$

where $\tau$ denotes the tangent direction on the boundary point $x$. As $n$ approaches zero, the free term is $-\frac{\pi}{2} \frac{\partial u(x)}{\partial \tau}$.

(6). Tangent derivative of double-layer potential due to $M^{\tau}(s, x)=2 y_{i} y_{j} n_{i} \bar{n}_{j} / r^{4}-n_{i} \bar{n}_{i} / r^{2}=\cos (\theta) / n^{2}$ :

Similar to Eq. (20), we only change the normal derivative to tangent derivative as

$$
\begin{aligned}
& n(x) \rightarrow \tau \\
& \int_{B_{n}} M^{\tau}(s, x) u(s) d B(s)=\frac{\pi}{2} \frac{\partial u(x)}{\partial \tau}
\end{aligned}
$$

It is found that the tangent derivative of potential can also be expressed in terms of superposition of all the state variables, which include the potential and the normal derivative of potential on the boundary which are solved by using the $U T$ or $L M$ equations. Therefore, we can derive the dual boundary integral equations and the expression for the tangential flux along the boundary as follows:

$$
\begin{array}{r}
\pi u(x)=C . P . V \cdot \int_{B} T(s, x) u(s) d B(s) \\
-R . P . V \cdot \int_{B} U(s, x) t(s) d B(s) \\
\pi t(x)=H . P . V \cdot \int_{B} M(s, x) u(s) d B(s) \\
-C . P . V \cdot \int_{B} L(s, x) t(s) d B(s) \\
\pi \frac{\partial u(x)}{\partial \tau}=H . P . V \cdot \int_{B} M^{\tau}(s, x) u(s) d B(s) \\
\quad-C . P . V \cdot \int_{B} L^{\tau}(s, x) t(s) d B(s)
\end{array}
$$

after using

$$
\begin{aligned}
& \int_{B^{\prime}+B^{-}+B^{+}} U(s, x) t(s) d B(s)=R . P . V . \int_{B} U(s, x) t(s) d B(s) \\
& \int_{B^{\prime}+B^{-}+B^{+}} T(s, x) u(s) d B(s)=C . P . V \cdot \int_{B} T(s, x) u(s) d B(s)
\end{aligned}
$$




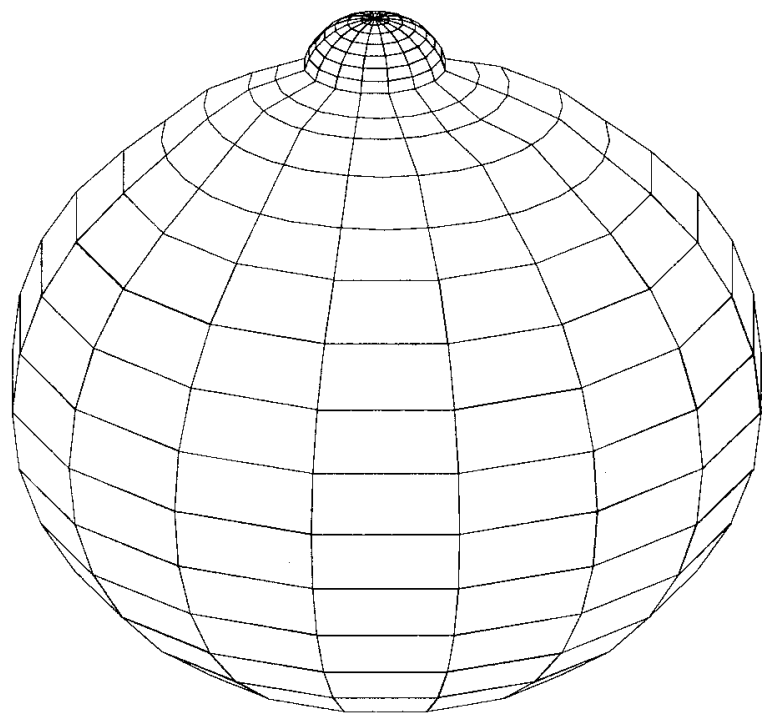

Fig. 3. The considered boundary integration path for the three-dimensional Laplace problem.

$\int_{B^{\prime}+B^{-}+B^{+}} L(s, x) t(s) d B(s)=C . P . V \cdot \int_{B} L(s, x) t(s) d B(s)$

$\int_{B^{\prime}+B^{-}+B^{+}} M(s, x) u(s) d B(s)=H . P . V \cdot \int_{B} M(s, x) u(s) d B(s)$

$$
+\frac{2}{n} u(x)
$$

$\int_{B^{\prime}+B^{-}+B^{+}} L^{\tau}(s, x) t(s) d B(s)=C . P . V . \int_{B} L^{\tau}(s, x) t(s) d B(s)$

$\int_{B^{\prime}+B^{-}+B^{+}} M^{\tau}(s, x) u(s) d B(s)=H . P . V \cdot \int_{B} M^{\tau}(s, x) u(s) d B(s)$

\section{FREE TERMS OF DUAL INTEGRAL}

\section{FORMULATION WITH A SMOOTH BOUNDARY} FOR THE THREE DIMENSIONAL CASE

Similarly, we can extend the two-dimensional case to the three-dimensional case in Fig. 3. Eq. (1) (3) reduce to

$$
\begin{aligned}
& 4 \pi u(x)=\int_{B^{\prime}+B^{-}+B_{n}+B^{+}}\{T(s, x) u(s)-U(s, x) t(s)\} d B(s) \\
& 4 \pi t(x)=\int_{B^{\prime}+B^{-}+B_{n}+B^{+}}\{M(s, x) u(s)-L(s, x) t(s)\} d B(s) \\
& 4 \pi \frac{\partial u(x)}{\partial \tau}=\int_{B^{\prime}+B^{-}+B_{n^{+}} B^{+}}\left\{M^{\tau}(s, x) u(s)\right. \\
& \left.-L^{\tau}(s, x) t(s)\right\} d B(s)
\end{aligned}
$$

where $U(s, x)=-1 / r$. Without loss of generality, we (a) $U(s, x)$

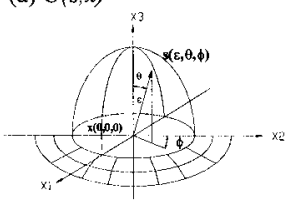

Domain

(c) $L(s, x)$

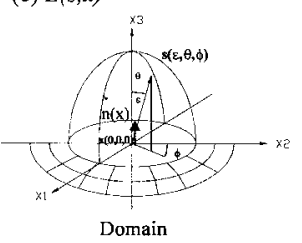

(b) $T(s, x)$

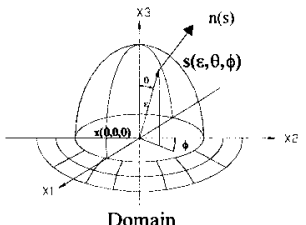

(d) $M(s, x)$

Fig. 4. Related symbols around a smooth boundary for the three-dimensional Laplace problem.

have the following notations in Fig. 4:

$x=(0,0,0)$

$s=(\mathrm{n} \sin \theta \sin \phi, \mathrm{n} \sin \theta \cos \phi, \mathrm{n} \cos \theta)$

$r=|x-s|$

$y_{1}=-\mathrm{n} \sin \theta \sin \phi$

$y_{2}=-\mathrm{n} \sin \theta \cos \phi$

$y_{3}=-\mathrm{n} \cos \theta$

$n(s)=\left(n_{1}, n_{2}, n_{3}\right)$

$=(\sin (\theta) \sin (\phi), \sin (\theta) \cos (\phi), \cos (\theta))$

$n(x)=\left(\bar{n}_{1}, \bar{n}_{2}, \bar{n}_{3}\right)=(0,0,1)$ for normal derivative

$\tau_{1}=\left(\bar{n}_{1}, \bar{n}_{2}, \bar{n}_{3}\right)=(1,0,0)$ for tangent derivative

$\tau_{2}=\left(\bar{n}_{1}, \bar{n}_{2}, \bar{n}_{3}\right)=(0,1,0)$ for tangent derivative

$$
\begin{aligned}
u(s) & =u(x)+\left.\frac{\partial u}{\partial x_{1}}\right|_{s=x} n \sin \theta \sin \phi \\
& +\left.\frac{\partial u}{\partial x_{2}}\right|_{s=x} n \sin \theta \cos \phi+\left.\frac{\partial u}{\partial x_{3}}\right|_{s=x} n \cos \theta \\
t(s) & =\frac{\partial u(s)}{\partial s_{1}} \sin \theta \sin \phi+\frac{\partial u(s)}{\partial s_{2}} \sin \theta \cos \phi+\frac{\partial u(s)}{\partial s_{3}} \cos \theta
\end{aligned}
$$


where $0<\theta<\frac{\pi}{2}$, and $0<\phi<2 \pi$. The free terms of the six kernels on the three-dimensional case will be derived in the following.

(1). Single-layer potential due to $U(s, x)=-1 / r=-1 / \mathrm{n}$ :

$$
\begin{gathered}
\int_{B_{n}} U(s, x)\left[\frac{\partial u(s)}{\partial s_{1}} \sin \theta \sin \phi+\frac{\partial u(s)}{\partial s_{2}} \sin \theta \cos \phi\right. \\
\left.+\frac{\partial u(s)}{\partial s_{3}} \cos \theta\right] d B(s)=0
\end{gathered}
$$

As $\mathrm{n}$ approaches zero, the free term vanishes.

(2). Double-layer potential due to

$T(s, x)=-y_{i} n_{i} / r^{3}=1 / \mathrm{n}^{2}$ :

$$
\begin{aligned}
\int_{B_{n}} T(s, x)[u(x) & +\left.\frac{\partial u}{\partial x_{1}}\right|_{s=x} n \sin \theta \sin \phi \\
& +\left.\frac{\partial u}{\partial x_{2}}\right|_{s=x} n \sin \theta \cos \phi \\
& \left.+\left.\frac{\partial u}{\partial x_{3}}\right|_{s=x} n \cos \theta\right] d B(s)=2 \pi u(x)
\end{aligned}
$$

As $\mathrm{n}$ approaches zero, the free term is $2 \pi u(x)$.

(3). Normal derivative of single-layer potential due to $L(s, x)=y_{i} \bar{n}_{i} / r^{3}=-\cos (\theta) / n^{2}$ :

$$
\begin{gathered}
\int_{B_{n}} L(s, x)\left[\frac{\partial u(s)}{\partial s_{1}} \sin \theta \sin \phi+\frac{\partial u(s)}{\partial s_{2}} \sin \theta \cos \phi\right. \\
\left.+\frac{\partial u(s)}{\partial s_{3}} \cos \theta\right] d B(s)=-\frac{2 \pi}{3} t(x)
\end{gathered}
$$

As $n$ approaches zero, the free term is $-\frac{2 \pi}{3} t(x)$.

(4). Normal derivative of double-layer potential due to $M(s, x)=-n \bar{n}_{i} / r^{3}+3 y_{i} y_{j} n_{i} \bar{n}_{j} / r^{5}=2 \cos (\theta) / n^{3}:$

$$
\begin{aligned}
\int_{B_{n}} M(s, x) & {\left[u(x)+\left.\frac{\partial u}{\partial x_{1}}\right|_{s=x} n \sin \theta \sin \phi\right.} \\
+ & \left.\left.\frac{\partial u}{\partial x_{2}}\right|_{s=x} n \sin \theta \cos \phi+\left.\frac{\partial u}{\partial x_{3}}\right|_{s=x} n \cos \theta\right] d B(s) \\
= & \frac{4 \pi}{3} t(s)-\frac{2 \pi}{n} u(x)
\end{aligned}
$$

As $n$ approaches zero, the free term is $\frac{4 \pi}{3} \pi t(x)$. Also, a boundary term, $\frac{-2 \pi}{n} u(x)$, is present.

(5). Tangent derivative of single-layer potential due to $L^{\tau}(s, x)=y_{i} \bar{n}_{i} / r^{3}=-\cos (\phi) \sin (\theta) / n^{2}:$

Since the tangent derivative instead of the normal derivative is considered, we have

$$
n(x) \rightarrow \tau
$$

$$
\begin{gathered}
\int_{B_{n}} L^{\tau}(s, x)\left[\frac{\partial u(s)}{\partial s_{1}} \sin \theta \sin \phi+\frac{\partial u(s)}{\partial s_{2}} \sin \theta \cos \phi\right. \\
\left.+\frac{\partial u(s)}{\partial s_{3}} \cos \theta\right] d B(s)=-\frac{2 \pi}{3} \frac{\partial u(x)}{\partial \tau}
\end{gathered}
$$

As $n$ approaches zero, the free term is $-\frac{2 \pi}{3} \frac{\partial u(x)}{\partial \tau}$.

(6). Tangent dervative of double-layer potential due to $M^{\tau}(s, x)=-n_{i} \bar{n}_{i} / r^{3}+3 y_{i} y_{j} n_{i} \bar{n}_{j} / r^{5}=2 \cos (\phi) \sin (\theta) / n^{3}$ :

Similar to Eq. (52), we only change the normal derivative to tangent derivative as

$$
\begin{aligned}
& n(x) \rightarrow \tau \\
& \left.\int_{B_{n} M^{\tau}(s,}, x\right)\left[u(x)+\left.\frac{\partial u}{\partial x_{1}}\right|_{s=x} n \sin \theta \sin \phi\right. \\
& \quad+\left.\frac{\partial u}{\partial x_{2}}\right|_{s=x} n \sin \theta \cos \phi \\
& \left.\quad+\left.\frac{\partial u}{\partial x_{3}}\right|_{s=x} n \cos \theta\right] d B(s)=\frac{4 \pi}{3} \frac{\partial u(x)}{\partial \tau}
\end{aligned}
$$

As $n$ approaches zero, the free term is $\frac{4 \pi}{3} \frac{\partial u(x)}{\partial \tau}$.

It is interesting to find that the free term in the $L M$ equation is contributed by one-third from the $L$ kernel in Eq. (50) and two-thirds from the $M$ kernel in Eq. (51), respectively. All the above results are summarized in Table1.

\section{CONCLUSIONS}

The free terms of the dual boundary integral equations for the two-dimensional and three-dimensional Laplace problems were derived. The $L$ and $M$ kernels for the two-dimensional problem resulted in the free terms of $-\frac{\pi}{2} t(x)$ and $\frac{\pi}{2} t(x)$, respectively, while the $L$ and $M$ kernels for the three-dimensional problem resulted in the free terms of $-\frac{2 \pi}{3} t(x)$ and $\frac{4 \pi}{3} t(x)$, respectively. Although the free terms are not the same in the intermediate process, their final results are the same to those deriving by using the limiting process.

\section{NOTATIONS}

$B E M \quad$ boundary element method

$B^{\prime}, B^{+}, B_{\mathrm{n}}, B^{-} \quad$ contour integration path including the singularity

R.P.V. Riemann principal value

C.P.V. Cauchy principal value

H.P.V. Hadamard principal value

$U(s, x) \quad$ kernel function of the first dual integral equation 


\begin{tabular}{|c|c|}
\hline$T(s, x)$ & $\begin{array}{l}\text { kernel function of the first dual integral } \\
\text { equation }\end{array}$ \\
\hline$L(s, x)$ & $\begin{array}{l}\text { kernel function of the second dual inte- } \\
\text { gral equation }\end{array}$ \\
\hline$L^{\tau}(s, x)$ & $\begin{array}{l}\text { kernel function for the tangent deriva- } \\
\text { tive of the single-layer potential }\end{array}$ \\
\hline$M(s, x)$ & $\begin{array}{l}\text { kernel function of the second dual inte- } \\
\text { gral equation }\end{array}$ \\
\hline$M^{\tau}(s, x)$ & $\begin{array}{l}\text { kernel function for the tangent deriva- } \\
\text { tive of the double-layer potential }\end{array}$ \\
\hline$x$ & position vector of field point \\
\hline$s$ & position vector of source point \\
\hline$u(x)$ & potential on the boundary point $x$ \\
\hline$u(s)$ & potential on the boundary point $s$ \\
\hline$n_{i}$ & normal vector of field point $x$ \\
\hline $\bar{n}_{i}$ & $\begin{array}{l}\text { normal (tangent) vector of source point } \\
s\end{array}$ \\
\hline$t(s)$ & normal flux on the boundary point $s$ \\
\hline$t(x)$ & normal flux on the boundary point $x$ \\
\hline$\tau_{1}$ & $\begin{array}{l}\text { tangent direction on the boundary point } \\
x\end{array}$ \\
\hline$\tau_{2}$ & $\begin{array}{l}\text { tangent direction on the boundary point } \\
x\end{array}$ \\
\hline $\mathrm{n}$ & $\begin{array}{l}\text { radius of the contour integration around } \\
\text { the singularity }\end{array}$ \\
\hline & polar coordinate \\
\hline$(\mathrm{n}, 6$ & spherical coordinate \\
\hline
\end{tabular}

\section{REFERENCES}

1. Alarcon, E., Martin A. and Paris F., "Boundary elements in potential and elasticity theory," Computers and Structures, Vol. 10, pp. 351-362 (1979).

2. Aliabadi, M.H., Hall, W.S. and Phemister, T.G., "Taylor expansions in the boundary element methods for Neumann problems," Boundary Elements VII, edited by C. A. Brebbia and G. Maier, 12.31-12.39, Computational Mechanics Publication (1985)

3. Aliabadi, M.H., Hall, W.S. and Phemister, T.G., "Taylor expansions for singular kernels in the boundary element method," Int. J. Numer. Meth. Engng., Vol. 21, pp. 22212236 (1985).

4. Banerjee, P.K. and Butterfield, R., "Boundary Element Methods in Engineering Science," McGraw-Hill, London, (1981).

5. Chen, J.T., " On Hadamard principal value and boundary integral formulation of fracture mechanics, " Master Thesis, Institute of Applied Mechanics, National Taiwan University (1986).

6. Chen, J.T. and Hong H.-K., " On the dual integral representation of boundary value problem in Laplace equation," Boundary Elements Abstracts, Vol. 4, No 3, pp. 114-116 (1993).

7. Chen, J.T. and Hong, H.-K., Boundary Element Method, 2nd Ed., New World Press, Taipei, Taiwan, (1992)(in Chinese)

8. Chen, J.T., Hong, H.-K. and Chyuan, S.W., "Boundary element analysis and design in seepage flow problems with sheetpiles," Finite Elements in Analysis and Design, Vol. 17, pp. 1-20 (1994).

9. Chen, J.T. and Hong, H.-K., "Dual boundary integral equations at a corner using contour approach around singularity," Advances in Engineering Software, Vol. 21, pp. 167-178 (1994).

10. Chen, J.T. and Chen, K.H., "Dual integral formulation for determining the acoustic modes of a two-dimensional cavity with a degenerate boundary," Engineering Analysis with Boundary Elements, Vol. 21, No. 2, pp. 105-116 (1998).

11. Chen, J.T. and Hong, H.-K., "Review of dual boundary element methods with emphasis on hypersingular integrals and divergent series," Applied Mechanics Reviews, ASME, Vol. 52, No. 1, pp. 17-33 (1999).

12. Cruse, T.A. and Suwito, W., "On the Somigliana stress identity in elasticity," Computational Mechanics, Vol. 11, No. 1, pp. 1-10 (1993).

13. Davi, G. and Milazzo, A., "Symmetric and positive definite variational BEM for 2-D free vibration analysis," Engineering Analysis with Boundary Elements, Vol. 14, No. 4, pp. 343-348 (1994).

14. Donald, E., Cormack. and Rosen, Dan., "Gauge conditions and the analysis of singular fields with boundary integral equations," Engineering Analysis with Boundary Elements, Vol. 18, No. 1, pp. 1-8 (1996).

15. Elschner, J., Graham, I.G., "An optimal order collocation method for first kind boundary integral equations on polygons," Numer. Math., Vol. 70, pp. 1-31 (1995).

16. Elschner, J., Jeon, Y., Sloan, I.H. and Stephan, E.P., "The colloaction method for mixed boundary boundary value problems on domains with curved polygonal boundaries," to Appear in Numer. Math. .

17. Gray, L.J., "Numerical experiments with a boundary element technique for corners," Advances in Boundary Elements, Vol. 1, pp. 243-250 (1989).

18. Gray, L.J. and Lutz, E., "On the treatment of corners in the boundary element method," J. Comp. Appl. Math., Vol. 32, pp. 369-386 (1990).

19. Gray, L.J., "Electroplating corners," Computational Engineering with Boundary Elements, Vol. 1, pp. 63-72 (1990).

20. Gray, L.J. and Manne, L.L., "Hypersingular integrals at a corner," Engineering Analysis with Boundary Elements, Vol. 11, pp. 327-334 (1993).

21. Guiggiani, M., "Hypersingular boundary integral equations have an additional free term," Computational Mechanics, Vol. 16, pp. 245-248 (1995).

22. Günter N.M., Potential Theory and Its Applications to Basic Problems of Mathematical Physics, Frederick 
Ungar Publishing, Co., N.Y., (1967).

23. Hong, H.-K. and Chen, J.T., "Derivation of integral equations in elasticity," J. Engng. Mech. Div., ASCE, Vol. 114, No. 6, pp. 1028-1044 (1988).

24. Kebir, H., Roelandt, J.M. and Foulquier, J., “A new singular boundary element for crack problems application to bolted joints," Engineering Fracture Mechanics, Vol. 62, pp. 497-510 (1999).

25. Kisu, H. and Kawahara, T., Boundary element analysis system based on a formulation with relative quantity, BEM10 Conference, Comp. Mech. Publ., Southampton, (1988).

26. Kitahara, M. and Nakagawa, K., "Analytical treatment of free term for 3-Dimensional Elastodynamic BEM," Advances in Solid and Fluid Mechanics Boundary Element Methods, (1990).

27. Liang, M.T. Chen, I.L., Kuo, S.R. and Chen, J.T., "Dual boundary integral equations for Helmholtz equation at a corner using contour approach around singularity," Engineering Analysis with Boundary Elements, Revised, (2000)

28. Lutz, E., Gray L.J. and Ingraffea, A.R., "An overview of integration methods for hypersingular boundary integrals," Comp. Mech. Publ., Proc. BEM13 Conference, Southampton (1991).

29. Mansur, W.J. and Fleury, P.Jr., "Vector approach to the hypersingular BEM formulation for Laplace's equation in 2-D," Boundary Elements Communications, Vol. 8, No. 4, pp. 239-250 (1997).

30. Mantic, V., "On computing boundary limiting values of boundary integral with strongly singular and hypersingular kernels in 3-D BEM for Elastostatics," Engng Anal. Boundary Element, Vol. 12, pp. 115-134 (1985).

31. Mantic, V., "A new formula for the C-matrix in the Somigliana identity," J. Elasticity, Vol. 33, pp. 191-201 (1993).

32. Mantic, V. and Paris, F., "Existence and evaluation of the two free terms in the hypersingular boundary integral equation of potential theory," Engineering Analysis with Boundary Elements, Vol. 16, pp. 253-260 (1995).

33. Maucher, R. and Hartmann, F., "Corner singularities of Kirchhoff plates and boundary element method," Comput. Methods Appl. Mech. Engng., Vol. 173, pp. 273-285 (1999).
34. Portela, A., Aliabadi, M.H. and Rooke, D.P., “ The dual boundary element method : Effective implementation for crack problems," Int. J. Numer. Meth. Engng., Vol. 33, pp. 1269-1287 (1992).

35. Rosen, Dan. and Donald, E. and Cormack., "Singular and near singular integrals in the BEM: A Global approach," Journal on Applied Mathematics, Vol. 53, No. 2, pp. 340-357 (1993).

36. Tuck, E.O., "Application and solution of Cauchy singular integral equations," The Application and Numerical Solution of Integral Equations, ed. R. S. Anderson et al., Sijthoff and Noordhoff, (1980).

37. Walker, S.P. and Fenner, R.T., "Treatment of corners in BIE analysis of potential problems," Int. J. Numer. Meth. Engng., Vol. 28, pp. 2569-2581 (1989).

38. Young, A., "Improved numerical method for the traction boundary integral equation by application of Stokes' theorem," Int. J. Numer. Meth. Engng., Vol. 40, pp. 3141-3161 (1997).

\section{二維及三維Laplace問題之對偶邊界 元素法自由項的研究}

$$
\begin{array}{lllll}
\text { 陳 } & \text { 正宗 郭 世 } & \text { 第 } \\
\text { 陳 } & \text { 韋 } & \text { 誌 } & \text { 劉 } & \text { 偉 }
\end{array}
$$

海洋大學河海工程學系

$$
\text { 摘 要 }
$$

本文探討Laplace方程式的對偶邊界積分方程之 自由項。針對圍繞在平滑邊界上奇異點周圍的半圆 (二維) 或半球面 (三維) 積分可導得自由項。在二 維問題中, 自由項的來源有二, 一半來自 $L$ 核函數, 另一半來自 $M$ 核函數。意即自由項分別由 $L$ 核函數與 $M$ 核函數各貢獻一半。這個過程雖不同於極限方法從 域内點逼近到邊界點中, 跳躍項完全來自 $L$ 核函數所 貢獻, 但是最終的結果仍然是相同的。在超奇異積分 方程中, 阿達馬主值的觀念在此從隻層勢能的法向微 分推廣到切向微分。有趣的是, 在三維問題中, 我們 發現到自由項分別來自 $L$ 核函數的三分之一貢獻與 $M$ 核函數的三分之二貢獻。 